\title{
Reflexões sobre Gêneros, Tecnologia e Processo Vocacional
}

\author{
Karen da Silva Figueiredo, Cristiano Maciel \\ Programa de Pós-Graduação em Educação, Instituto de Educação, Universidade Federal \\ do Mato Grosso (UFMT), Cuiabá, Mato Grosso, Brasil \\ kareneic.ufmt.br, cmacieleufmt.br
}

\begin{abstract}
This paper aims to analyze theoretical issues related to gender, technology and vocational process in order to discuss how gender could influence the decision-making of the female high school students' vocational process in choosing CTE courses.
\end{abstract}

Resumo. Este trabalho analisa aportes teóricos relacionados às relações de gênero, tecnologia e processo vocacional a fim de discutir como o gênero poderia influenciar nas tomadas de decisão do processo vocacional de jovens alunas de Ensino Médio para ingresso em cursos de superiores de CET.

\section{Introdução}

A escolha de uma profissão é uma das primeiras grandes responsabilidades exigidas aos jovens, um momento de decisão que geralmente é engatilhado no período do Ensino Médio (EM) [McWhirter et al. 2000]. Considerando que a escolha profissional impacta não somente a dimensão da carreira, mas também outras dimensões pessoais como família, lazer, saúde etc., é de fundamental importância que esta escolha seja feita pelos jovens com consciência dos seus interesses e aptidões e total liberdade para priorizarem os seus valores pessoais. Segundo Saavedra (2009), os gêneros destacam-se como barreiras que mais limitam a liberdade de escolha dos e das jovens, influenciando a forma como concretizam as suas decisões ao longo do ciclo de vida. Taveira (2000) distingue os gêneros como variável capaz de influenciar na exploração e indecisão vocacional, interferindo na concretização de projetos vocacionais.

Dados quantitativos [Portal Brasil 2015; Saavedra 2009] apontam que a presença de mulheres em cursos de Ensino Superior das áreas de Computação, Engenharias e Tecnologias (CET) é muito baixa quando comparada a outras áreas. Entretanto, pesquisas mostram que o número de jovens de ambos os sexos que se interessam por estas áreas de conhecimento é praticamente idêntico até os treze anos de idade [Saavedra et al. 2010]. A partir dos treze anos, é possível verificar o decréscimo no número de jovens do sexo feminino que escolhem estes domínios tipicamente masculinos, em todos os níveis de ensino subsequentes [Xu 2008].

Para Jacobs (1996), as teorias educacionais e pesquisas estão focadas em disparidades de classes e quando as relações de gênero são discutidas, recebem pouca atenção. Pocinho et al. (2010) acrescentam o fato de que: no que diz respeito a estudos sobre indecisão de carreira, é ainda escasso o registo de diferenças de gêneros. Assim, o objetivo deste trabalho é analisar aportes teóricos relacionados às relações de gênero, tecnologia e processo vocacional. Tal atividade faz parte de uma pesquisa maior que intenta averiguar como o gênero poderia influenciar nas tomadas de decisão do processo 
vocacional de alunas de EM, para ingresso em cursos de Ensino Superior em CET.

\section{Gêneros e Tecnologia}

Historicamente, os campos da ciência e tecnologia foram percebidos como espaços de atuação masculina, sendo também associados à características comumente atribuídas aos homens, tais como: neutralidade, objetividade, imparcialidade e universalidade [Muzi e Da Luz 2012]. Graña (2004) aponta a associação do homem com o domínio da ciência, que por sua vez domina a natureza, considerada passiva e associada ao feminino. A existência dessa associação que reforça modelos patriarcais faz parecer que os homens estiveram e sempre estarão no domínio de todas as ordens do saber. Por conseguinte, a aproximação de mulheres nestes campos nem sempre foi estimulada. As mulheres começaram a avançar no domínio da ciência e tecnologia a partir de questionamentos sobre o determinismo biológico que as mantinha majoritariamente em atividades consideradas como mais adequadas ao seu sexo [Muzi e Da Luz 2012].

Foi a conhecida segunda onda do feminismo, nas décadas de 60 e 70, que detectou o apagamento e a minimização das mulheres na história da ciência e tecnologia [Brunet e Natansohn 2012]. Segundo Wacjman (2006) podem ser analisadas três posições teóricas em relação às feministas dessa época e a tecnologia: o feminismo liberal, o feminismo radical e o feminismo socialista.

Descrevendo resumidamente conforme Brunet e Natansohn (2012), o feminismo liberal considera que todo o problema da separação histórica das mulheres e a tecnologia se reduz a uma questão de acesso e oportunidades. A tecnologia seria neutra e os problemas poderiam ser resolvidos com políticas de igualdade de oportunidades. $\mathrm{O}$ feminismo radical considera que as tecnologias reprodutivas são instrumentos de eugenia, controle racial e patriarcal, colocando o problema da opressão das mulheres nas suas capacidades reprodutivas. Já o feminismo socialista reinsere a crítica de Marx às tecnologias e à divisão de trabalho, incorporando discussões de gêneros às discussões de classe e trabalho doméstico. A tecnologia seria considerada uma extensão da dominação patriarcal e capitalista e as mulheres seriam suas vítimas.

Atualmente, na terceira onda, conta-se com as discussões do ciberfeminismo, surgido na década de 90 com trabalhos conhecidos de Plant, Haraway e Turkle [Brunet e Natansohn 2012]. O ciberfeminismo traz uma visão otimista da tecnologia, em um discurso mais atrativo para as mulheres jovens que cresceram imersas na cultura digital. O ciberfeminismo deixa a "tecnofobia" para trás e enxerga a tecnologia como aliada para empoderamento feminino, mudanças políticas e organização e articulação de ideias e saberes. Com estes princípios, emergem uma série de políticas e iniciativas, como as já citadas na seção 2 , unindo a visão ciberfeminista do empoderamento tecnológico feminino com um pouco do viés de criação de oportunidades do feminismo liberal.

Hoje, as mulheres já são maioria como usuárias da internet, maioria nas redes sociais e maioria entre os jogadores de jogos eletrônicos. O desafio maior está em transformar estas mulheres de simples consumidoras de tecnologia em produtoras de tecnologia, participando ativamente do projeto e desenvolvimento dos produtos.

\section{Processo Vocacional}

Uma das principais características da adolescência é o desenvolvimento de vários 
aspectos da identidade e a formação de planos de carreira desempenha um importante papel no processo de formação dessa identidade, a identidade vocacional [Super, 1963]. A identidade vocacional deveria refletir um padrão de interesses e objetivos do jovem. Entretanto, a teoria de aprendizagem de Bandura (1986) e a Teoria Social Cognitiva do Desenvolvimento de Carreira de Lent et al. (2002) chamaram atenção para a influência de fatores cognitivos que antecedem o desenvolvimento de interesses e objetivos e para a avaliação da autoeficácia.

As pessoas tendem a acreditar que possuem capacidade de desempenhar determinados comportamentos e este fato determina o quão bem elas vão se engajar nestes comportamentos. O contrário também é verdade. Para os teóricos sociais cognitivos de carreira, autoeficácia é um fator crucial que media os interesses, objetivos e desenvolvimento de ações em um domínio em particular [Gushue et al. 2006].

Apesar da escolha de uma profissão já não ser necessariamente uma decisão para a vida toda, é um ponto colocado para os jovens como uma grande responsabilidade, culminando usualmente no período do EM sobre qual caminho seguir: procurar determinado emprego, fazer um curso técnico ou de nível superior em determinada área do conhecimento. Como o processo vocacional e a tomada de decisão é importante nos anos do EM, os jovens examinam a carreira sob uma perspectiva de avaliação da sua autoeficácia [Taylor e Betz 1983].

Segundo Saavedra (2009), a autoeficácia pode afetar os interesses vocacionais das jovens. Para a autora, as adolescentes evitam estas áreas por uma série de fatores: dificuldade de realização pessoal com a matemática, pouca exposição a modelos de mulheres em domínios não tracionais, maiores níveis de ansiedade nas tarefas associadas ao masculino e menor encorajamento de prosseguirem em uma carreira profissional. Pode concluir-se que, de uma forma geral, "meninas e mulheres possuem expectativas de autoeficácia a carreiras mais baixas e menos generalizadas do que os homens" [Saavedra 2009], explicando a subexploração das suas capacidades em áreas não popularmente consideradas femininas e a limitação de suas escolhas profissionais.

\section{Conclusões}

Diante do exposto, os autores do presente trabalho acreditam que como parte da sociedade, cabe às universidades fomentar pesquisas sobre as questões relativas aos gêneros na educação e no mercado, fornecendo informações e ajudando a contribuir com soluções para os problemas levantados. Paridade de acesso das jovens nos cursos de CET não é uma questão somente de equidade de gêneros. Muzi e Da Luz (2012) destacam que a baixa participação de mulheres em cursos superiores de CET não é prejudicial só para as mulheres, mas sobretudo, para essas áreas de conhecimento e principalmente para a sociedade que não pode contar com a contribuição de metade da população na busca do desenvolvimento científico, tecnológico, econômico e principalmente social do país.

Desta forma, investir em pesquisas que investiguem a fundo como o gênero interfere na escolha vocacional de cursos de CET das jovens durante o EM pode contribuir para a sociedade em diversos níveis de desenvolvimento. Como passos futuros, os autores pretendem realizar uma pesquisa qualitativa exploratória acompanhando o percurso de formação do processo vocacional de alunas de EM. 


\section{Referências}

Bandura, A. (2002) "Social foundations of thought and action", In: The health psychology reader, p. 94-106.

Brunet, K. S. e Natansohn, G. (2012) "Labdebug: práticas de cultura digital livre para mulheres”, In: Gênero e Tecnologias. EdUFMT, p. 101-116.

Graña, F. (2004) "Ciencia y tecnologia desde uma perspectiva de género", Montevidéu: Faculdad de Humanidades y Ciencias de la Educación.

Gushue, G. V. et al. (2006) "The relationship of career decision-making self-efficacy, vocational identity, and career exploration behavior in African American high school students", In: Journal of Career Development, v. 33, n. 1, p. 19-28.

Jacobs, J. A. (1996) "Gender inequality and higher education", In: Annual Review of Sociology, p. 153-185.

Lent, R. W. et al. (2002) "Social cognitive career theory", In: Career choice and development, v. 4, p. 255-311.

McWhirter, E. H. et al. (2000) "The effects of high school career education on socialcognitive variables", In: Journal of Counseling Psychology, v. 47, n. 3, p. 330.

Muzi, J. L. C. e Da Luz, N. S. (2012) "Relações de gênero na UFTPR: participação das mulheres na produção científica e tecnológica”, In: Gênero e Tecnologias. Tecnologias do Gênero, EdUFMT, p. 69-84.

Pocinho, M. D. (2010) "Influência do género, da família e dos serviços de psicologia e orientação na tomada de decisão de carreira”, In: Revista Brasileira de Orientação Profissional, v. 11, n. 2, p. 201-212.

Portal Brasil. (2015) "Mulheres são maioria no ingresso e na conclusão de cursos superiores. Educação", Disponível em: <http://www.brasil.gov.br/educacao/2015/ 03/mulheres-sao-maioria-no-ingresso-e-na-conclusao-de-cursos-superiores>.

Saavedra, L. (2009) "Assimetrias de Género nas Escolhas Vocacionais" In: Guião de educação - Género e cidadania, Lisboa, CIG.

Saavedra, L. et al. (2010) "A subrepresentatividade das mulheres em áreas tipicamente masculinas: Factores explicativos e pistas para a intervenção", In: Revista Brasileira de Orientação Profissional, v. 11, n. 1, p. 49-59.

Super, D. E. (1963) "Vocational development in adolescents and early adulthood: Tasks and behaviors", In: Career development: Self concept theory, Research Monograph.

Taveira, M do C. (2000) "Exploração e desenvolvimento vocacional de jovens", Centro de Estudos em Educação e Psicologia, Universidade do Minho, 2000.

Taylor, K. M. e Betz, N. E. (1983) "Applications of self-efficacy theory to the understanding and treatment of career indecision", In: Journal of Vocational Behavior, v. 22, n. 1, p. 63-81.

Wajcman, J. (2006) "El tecnofeminismo", Universitat de València, Catedra, p. 200.

$\mathrm{Xu}$, Y. J. (2008) "Gender disparity in STEM disciplines: A study of faculty attrition and turnover intentions”, In: Research in Higher Education, v. 49, n. 7, p. 607-624. 